\title{
Delivery of a Feeding Obturator in a New Born Child: A Case Report
}

\author{
Mayank Trivedi', Jay Mehta ${ }^{2}$ \\ ${ }^{1}$ Senior Lecturer (Consultant Orthodontist), Department of Orthodontics \& Dentofacial Orthopedics, \\ Rajarajeswari Dental College and Hospital, Bangalore, India. \\ ${ }^{2}$ Consultant Prosthodontist and Implantologist, Proprietor at Dentoville Clinic, Rajawadi, Ghatkopar East \\ Mumbai, Maharashtra, India.
}

Case Report

Address for Correspondence Author

Dr. Mayank Trivedi; Department of Orthodontics \& Dentofacial Orthopedics, Rajarajeswari Dental College and Hospital, Bangalore, India.

E-mail: 1987.mayank@gmail.com

Crossref doi: https://doi.org/10.36437/ijdrd.2020.2.3.D

\begin{abstract}
Obturators are custom made plastic material that is made to fit the precise contour of the hard and the soft palate that extends onwards to seal off the mouth from the nasal cavity. Fabricated by an orthodontist or a prosthodontist, it requires frequent replacements as the baby grows and preferably given at 2-3 days after birth. Breastfeeding in a cleft baby is difficult although there are a few compromised techniques that are employed such as breastfeeding positions, compression technique, supplementer usage, and nipple shield alone or in combination. Once the obturator is delivered the child stops regurgitation or vomiting as the lining of the nasal cavity is protected. Breastfeeding is very essential as it also facilitates the proper development of jawbones and facial muscles and in order to do that feeding of a child since day one of birth is a very important pre-requisite that can be achieved by delivering an efficient palatal obturator.
\end{abstract}

Keywords: Diagnosis, Palatal Obturator, Feeding, Development, Cleft lip, Cleft Palate.

\section{Introduction}

To make an oral cavity ready for the desired functioning it is very essential to separate the oral cavity from nasal cavity and sinuses from the breach that may have developed due to defects that are congenital or acquired and requires to be dealt by a prosthetic or surgical repair of the defect. ${ }^{1}$

Incidence of cleft lip and palate being 0.28 to 3.74 per 1000 live birth is one the most common craniofacial condition in humans. A non-syndromic cleft lip or palate has a multifactorial origin whereas a syndromic type of cleft condition is characterised by Treacher Collin syndrome, Trisomies 13 and 18, Apert's syndrome, Wanderburg's syndrome Stickler's syndrome and Piere Robin Syndrome. ${ }^{2}$ A patient encountering a cleft condition may pose difficulties of deficiency in facial and dental growth along with articulation defects, 
eustachian tube dysfunction and velopharyngeal insufficiency. ${ }^{3}$ Keeping all these considerations in mind early diagnosis and treatment planning is mandatory.

Ultrasonography used for early diagnosis of such conditions is helpful in providing information to the parents in order to prepare them to handle such conditions by counselling and preparing them for the future. It also includes an examination of foetal anatomy, viability, gestational age, and the placental location. In case a foetal abnormality is detected, it is advisable to undergo further investigations procedures such as 3D/4D ultrasonography, foetal magnetic resonance imaging (MRI) along with other approaches such as molecular or chromosomal testing. ${ }^{4}$

Feeding plate being completely tissue supported significantly obturates the defect and provides complete restoration of the defect between oral and nasal cavities so that a definitive platform is created against which the baby can press the nipple and retrieve milk towards the oral cavity. ${ }^{5}$ Cleft palate is a craniofacial deformity that results in an early embryonic stage characterized by problems of feeding, nasopharyngeal reflex, regurgitation, prolonged feeding time and lack of weight gain which can be corrected using a palatal obturator that also facilitates maxillary growth and well-being of the patient. ${ }^{6}$

The aim of the present case report is to shed light on a feeding obturator/plate delivery via a case report in a newborn while keeping in mind the prenatal diagnosis and the postnatal care to be taken until the child is ready for surgery.

\section{Case Report and Procedure}

A 4 days old infant was admitted to the cleft care unit requiring immediate orthopaedic intervention for the fabrication of a palatal obturator as the infant was having feeding difficulties (figure 1). Upon extra-oral and intraoral examination, the presence of a unilateral cleft of lip and palate was seen on the left part of the oral cavity (figure 2). After a complete examination, parents were assured about the rehabilitation by providing a palatal acrylic plate for the defect. Keeping the position of the head in an upright position, maxillary impressions were made out of putty impression material (vinyl poly-siloxane) which is a fast-setting material and was loaded on to the fingers and adequately adapted upon the areas of the defect as it has a thick consistency and recorded the details of the tissues and undercuts adequately (figure 3). After the impression material was set it was poured using type III dental stone (Orthokal) for its flow-ability and toughness. As the cast was reproduced, it was assessed for the presence of any undercuts which were blocked using type $\mathrm{ll}$ modelling wax (figure $4 \mathrm{~A}$ ). An acrylic obturator fabrication was achieved with the process of polymerisation following which the acrylic was removed, trimmed for excess, finished, and polished before it was delivered. A silk thread was tied onto an extension at the anterior part of the tray for preventing any accidental swallowing into the oral cavity and for controlled handling (figure $4 \mathrm{~B}$ ). Insertion of the obturator was performed and parents were detailed about the use of the appliance and its handling (figure $5 \mathrm{~A}, \mathrm{~B}, \mathrm{C} \& \mathrm{D}$ ). They were taught about the placement, removal, and also about the cleaning of the appliance after feeding by using a piece of gauze. 


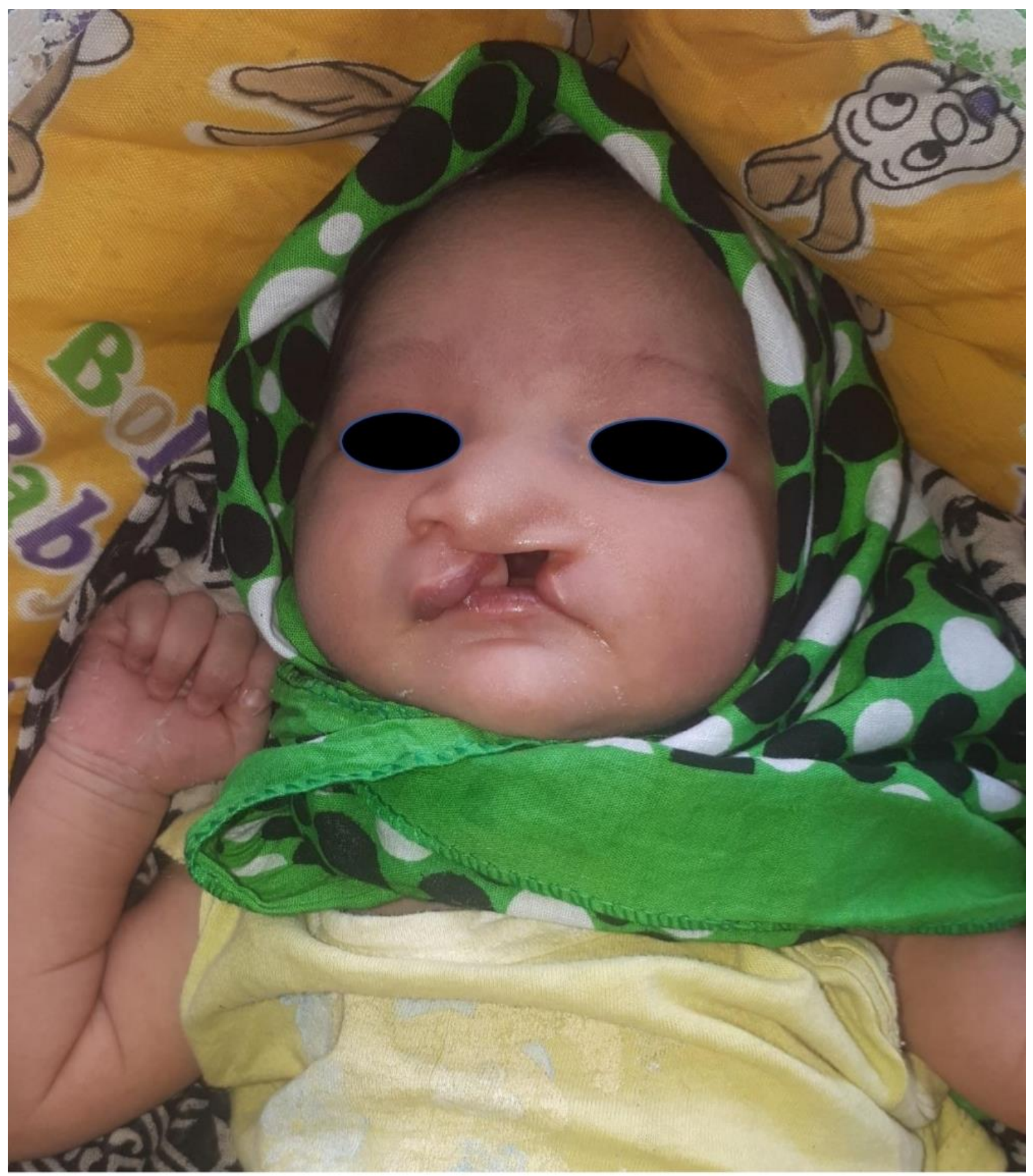

FIG 1: NEW BORN WITH PRESENCE OF UNILATERAL CLEFT LIP AND PALATE 


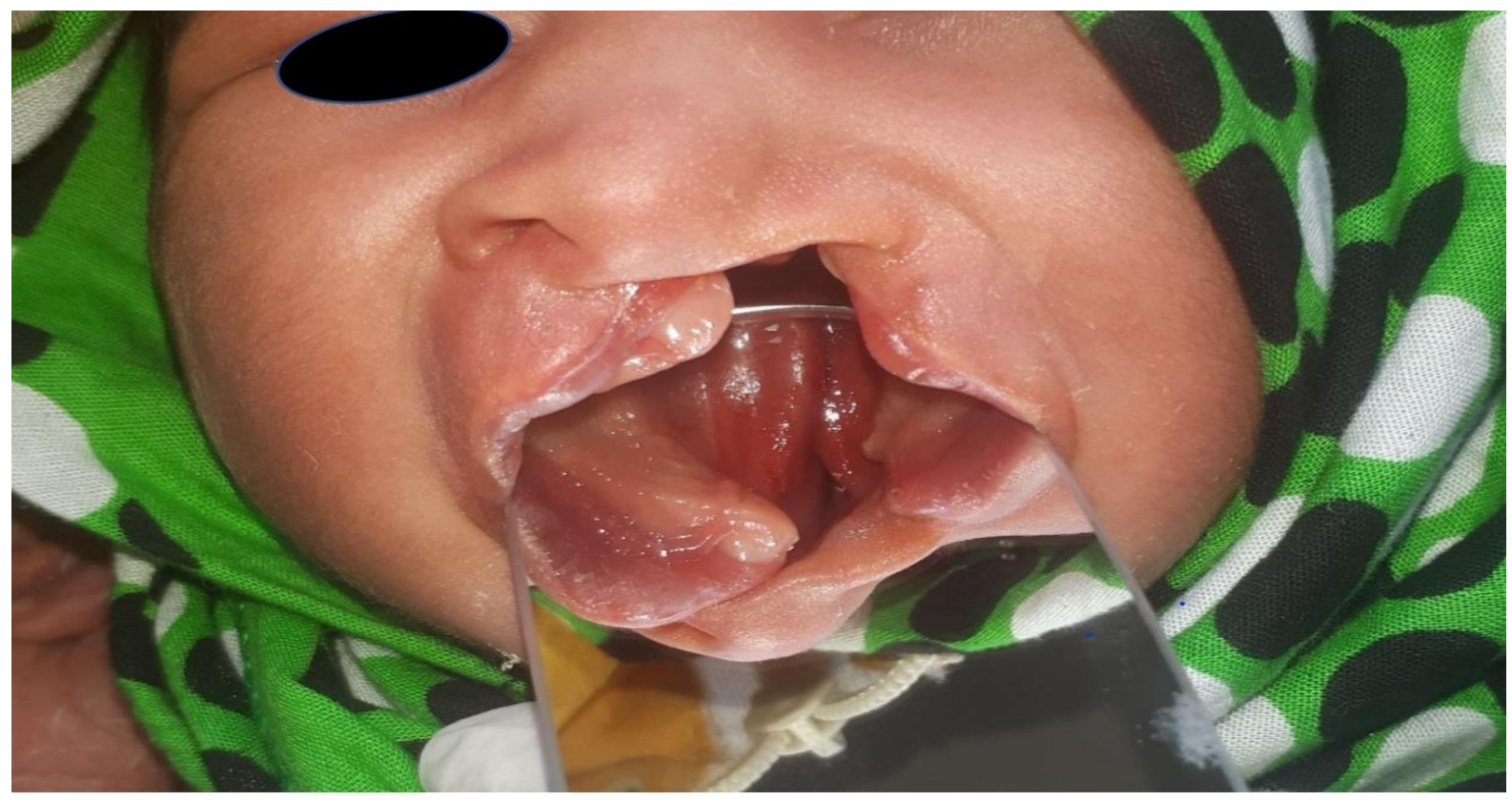

FIG 2: INTRAORAL VIEW OF UNILATERAL CLEFT LIP AND PALATE

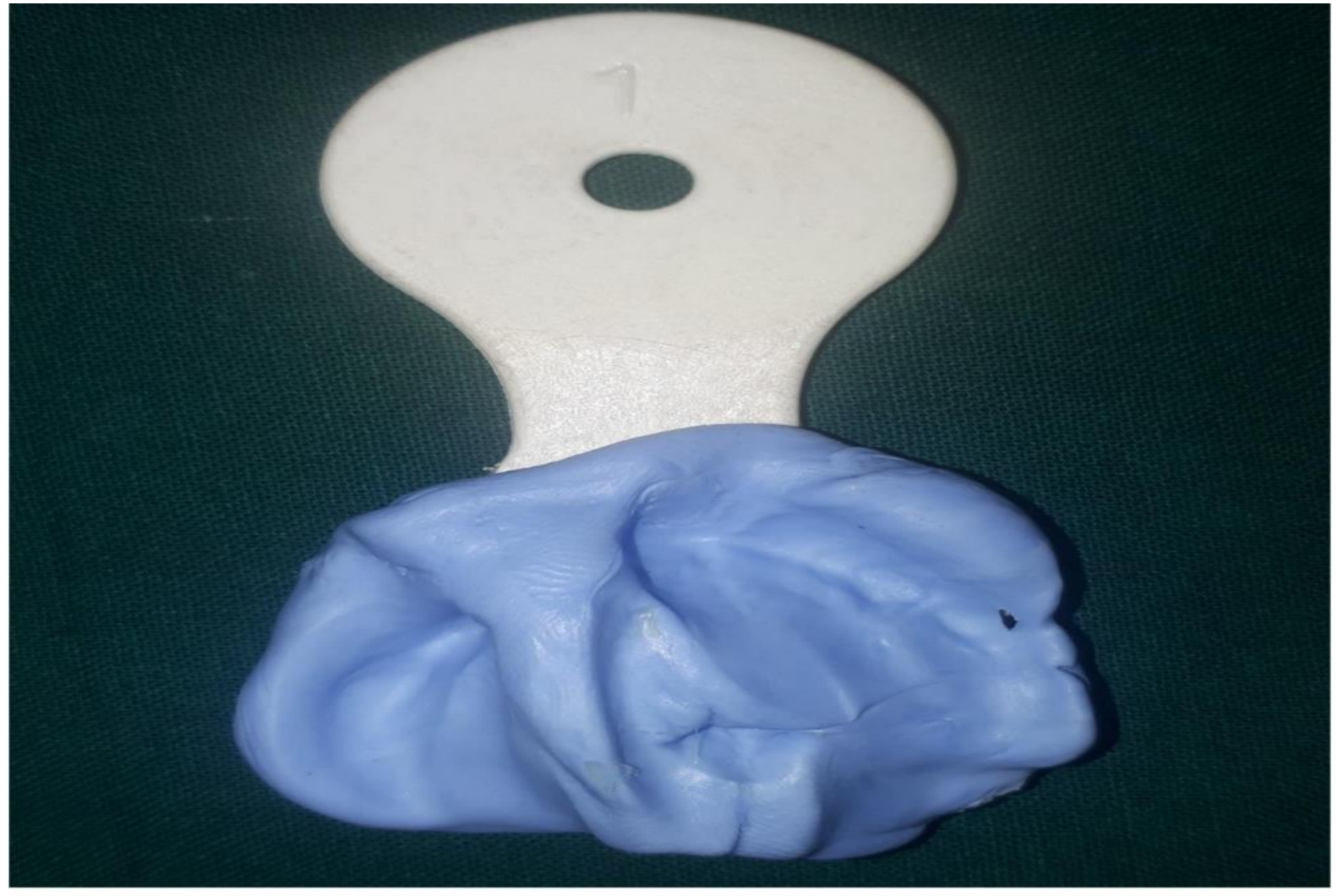

FIG 3: IMPRESSION OF THE MAXILLARY ARCH USING VINYL POLY-SILOXANE 

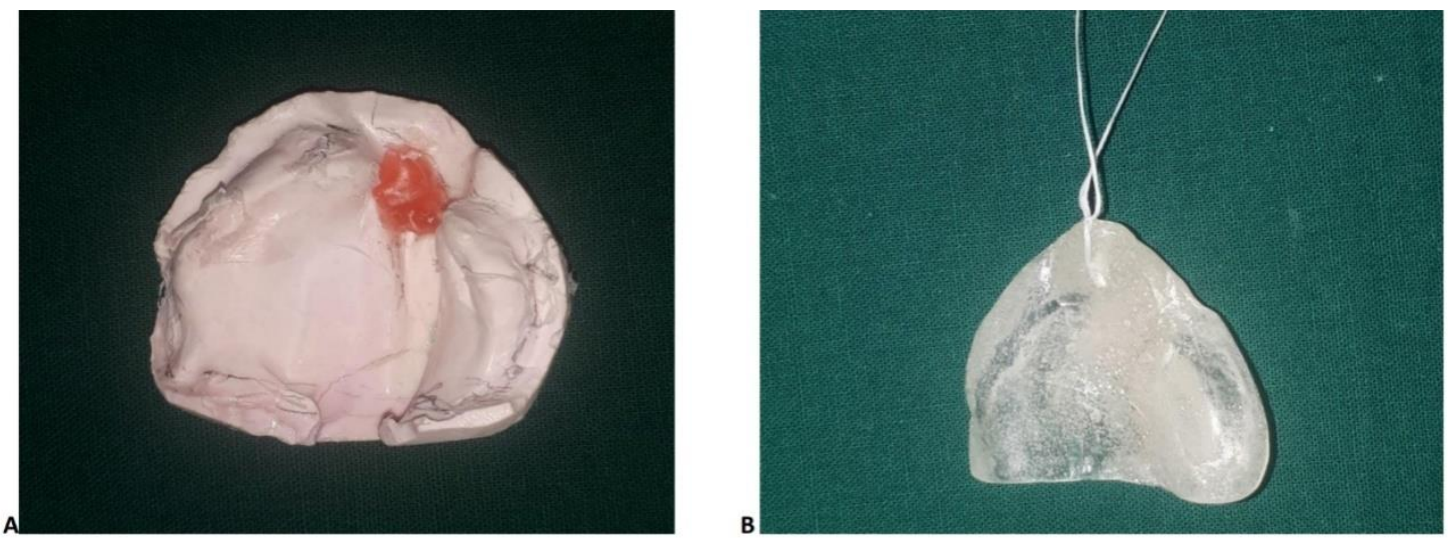

FIG 4: A-MAXILLARY CAST WITH BLOCKED UNDERCUTS AND B-FABRICATED PALATAL OBTURATOR WITH THREAD FOR EASE OF HANDLING
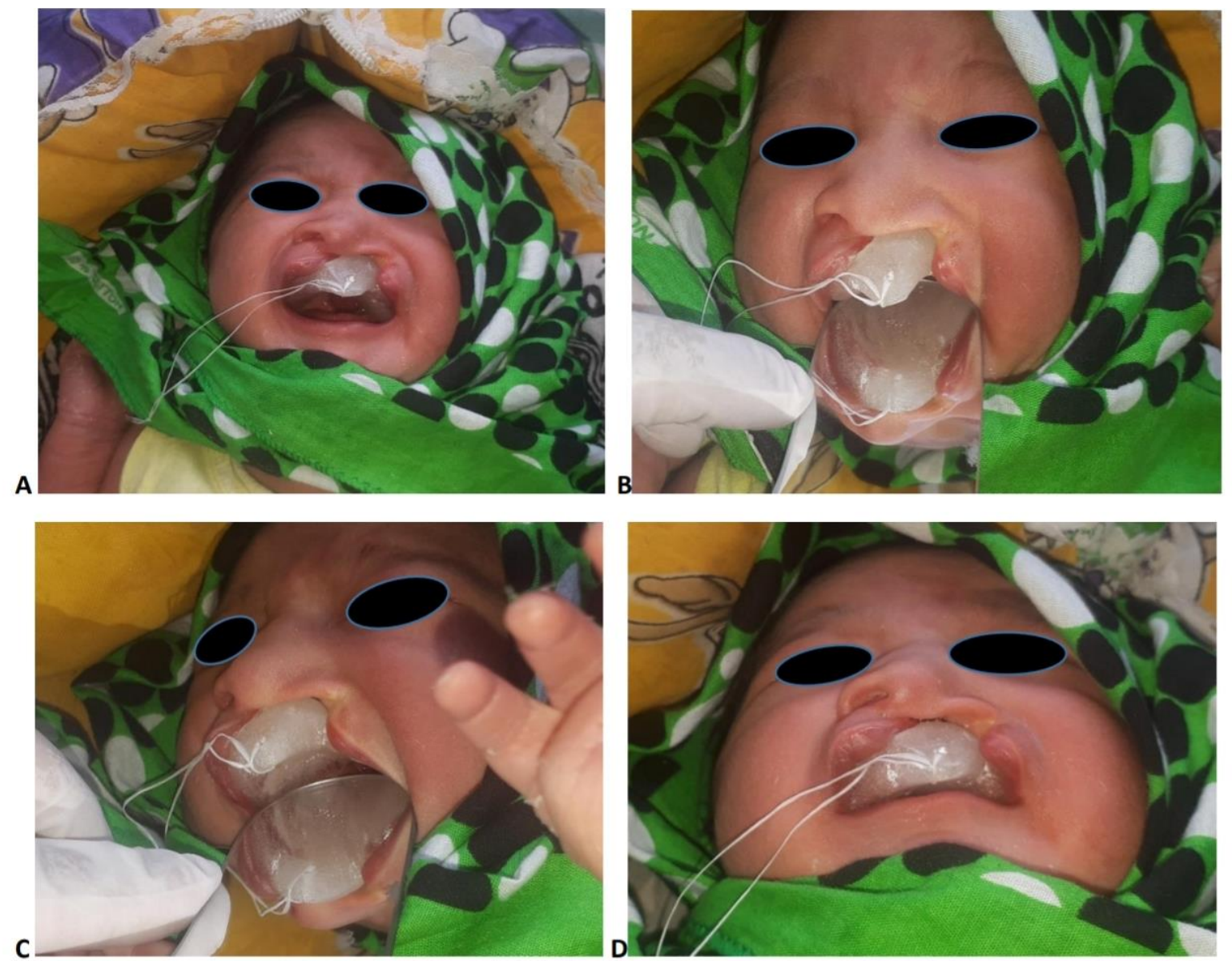

FIG 5 (A,B,C \& D): AFTER THE INSERTION OF THE OBTURATOR/FEEDING PLATE

17 International Journal of Drug Research and Dental Science 


\section{Discussion}

An individual's acceptance and integration in the society is of outmost importance and any kind of distortion than normal affects physiology, anatomy and most importantly the oral function of an individual. ${ }^{7}$ Prenatal diagnosis is a way of preparing the parents for future regarding the defect and versing the parents with advice, support, information and an expert care from the specialists and staff nurses for immediate post-natal care. ${ }^{8} \mathrm{~A}$ child born with cleft deformity presents with difficulty in feeding and its associated lack of nutrition because of nasal regurgitation of food, too much air intake, chocking and prolonged feeding time that affects the overall growth and development of the child. All these parameters are seen associated with a cleft patient as there exists a communication between the oral and nasal structure that makes it impossible for the child for sucking because of an inability to create a negative pressure required for the same. ${ }^{9}$

Delivering an obturator might be an easy task but making an impression is the most crucial step in the fabrication of an obturator. The impression material generally used for this purpose is putty type vinyl polysiloxane as it has a higher viscosity than reduces swallowing and aspiration, its inability to cause trauma to the soft tissues and its ability to produces good surface details even with multiple pours and stills having good dimensional stability. ${ }^{10}$

An obturator that is fabricated acts as a barrier between the nasal and the oral cavity upon which when an infant applies pressure, can suck the milk from the nipple and can also guard against the tongue entering the palatal shelves that would interfere with the growth of the palatal shelves towards the midline. ${ }^{11}$

An appropriate time for surgery is considered to be between 9-18 months when the condition of the child is suitable to undergo a general anaesthetic procedure, blood investigations, cultures, and sensitivity tests. Growth disturbances are to be minimised but not at the cost of any speech impairment as it could be an irreversible condition. Conditions of the cleft are to be treated in a multidisciplinary manner keeping in mind the important role played by ENT surgeon, plastic surgeon, orthodontist, and speech therapist. ${ }^{12}$

\section{Conclusion}

Cleft is one of the common congenital anomalies that poses problems related to feeding, speech, nasal regurgitation, and hearing. A feeding plate or an obturator has to be fabricated in order to deal with such conditions so that the infant is able to feed and restore normal body weight and be suitable for carrying out the surgical procedure at an appropriate time. It is also important to carry-out much-needed investigations in order to diagnose the condition of cleft at the earliest which is important for the psychological preparation of the parents and also to prepare the infant for the required surgery in the future.

\section{References}

1. Jural SK, Singh RD, Gupta DS. Split obturator: An innovative approach. Contemp Clin Dent 2011; 2(3):253-5. https://doi.org/10.4103/0976-237X.86486

2. Naveen BH, Prasad RS, Kashinath KR, Kumar S, Kalavathi SD, Laishram N. An innovative modified feeding appliance for an infant with cleft lip and cleft palate: A case report. J Family Med Prim Care 2019; 8:2134-6. https://doi.org/10.4103/jfmpc.jfmpc 327 19

3. Jones $\mathrm{M} \mathrm{H}$ and Chapman K L. Cognitive and Language Issues Associated with Cleft Lip and Palate. SEMINARS IN SPEECH AND LANGUAGE 2011; 32(2):127-140. https://doi.org/10.1055/s-00311277715

4. Mak ASL and Leung KY. Prenatal ultrasonography of craniofacial abnormality. Ultrasonography 2019; 38(1):13-24. https://dx.doi.org/10.14366\%2Fusg.18031

5. Srivastava N and Goyal P. "Palatal Obturator: An Update". EC Dental Science (2017); 9(3):124-127. 
6. Masih S, Chacko RA, Thomas AM, Singh N, Thomas R and Abraham D. Simplified feeding appliance for an infant with cleft palate. J Indian Soc Pedod Prev Dent 2014; 32:338-41. https://doi.org/10.4103/0970-4388.140970

7. Alhayek S, Alsalem M, Alotaibi Y and Omair A. Evaluation of facial appearance in patients with repaired cleft lip and palate: comparing the assessment of laypeople and healthcare professionals. Maxillofacial plastic and reconstructive surgery 2019; 41(5):1-5. https://doi.org/10.1186/s40902$\underline{019-0189-1}$

8. Hodgkinson PD, Brown S, Duncun D, et al. Management of children in cleft lip and palate: A review describing the application of multidisciplinary team working in this condition based upon the experiences of a regional cleft lip and palate centre in United Kingdom. Fetal and Maternal Medicine Review 2005; 16(1):1-27. https://doi.org/10.1017/S0965539505001452

9. Kar R, Singh AK, Mishra N et al. A novel feeding appliance made up of soft silicone-based denture liner for cleft palate patient. Int J Oral Health Sci 2015; 5(1):53-6. https://doi.org/10.4103/2231$\underline{6027.171156}$

10. Rathee $M$ and Tamrakar AK. Single Visit Custom Made Flexible Feeding Obturator for an Infant with Tetralogy of Fallot. Saudi J Med Med Sci 2015; 3:226-9. https://doi.org/10.4103/1658-631X.162033

11. Anil Kumar, Rajender Reddy E, Thabitha Rani $S$ et al. Feeding obturator with presurgical Nasoalveolar molding for a 2 day old neonate with cleft lip and palate. Indian J Dent Adv 2017; 9(2): 120-123. http://nacd.in/Ijda/09/02

12. Thomas C. Repair of cleft palate: Evolution and current trends. J Cleft Lip Palate CraniofacAnomal 2015; 2(1):6-10. https://doi.org/10.4103/2348-2125.150704

How to cite this Article: Mayank Trivedi'리 Jay Mehta ${ }^{2}$ : Delivery of a Feeding Obturator in A New Born Child: A Case Report

Int. J. Drug Res. Dental Sci., 2020; 2(3):13-19.

Crossref doi: https://doi.org/10.36437/ijdrd.2020.2.3.D

Source of Support: Nil, Conflict of Interest: Nil.

Received: 18-7-2020 Revised: 4-8-2020 Accepted: 10-8-2020 